\title{
Risk factors and morbidities associated with childhood obesity in sub-Saharan Africa: a systematic scoping review
}

Frederick Inkum Danquah', Monica Ansu-Mensah', Vitalis Bawontuo ${ }^{1,2}$, Matilda Yeboah', Roseline H. Udoh', Mohammed Tahiru ${ }^{1}$ and Desmond Kuupiel ${ }^{2,3^{*}}$ (D)

\begin{abstract}
Background: The rising burden of childhood obesity is a major public health concern, particularly in sub-Saharan Africa (SSA), where most health systems are weak and least prepared for complications that may arise. While the need for preventive action is increasingly recognized, policy implementation within the sub-region has often been inadequate, non-systematic, and ad hoc. This study described evidence on the risk factors and morbidities associated with childhood obesity in SSA.

Methods: Guided by the Arksey and O'Malley framework incorporating the Levac et al. recommendations, and the Joanna Briggs Institute guidelines, we conducted a scoping study to address the research question. Thorough keywords systematic search was conducted for potentially eligible articles in PubMed, Google Scholar, Web of Science, and CINAHL published between 2009 and June 2019. Articles obtained were screened independently by two investigators at the abstract and full text phases using the eligibility criteria. All relevant data were extracted by two investigators in parallel and thematic analysis conducted.

Results: A total of 337,229 articles were obtained from the database search of which 68 satisfied the inclusion criteria and were included for data extraction. These 68 included studies were conducted in 19 countries with the majority, 27.9\% (19/68) from South Africa followed by Nigeria with 20.6\% (14/68). Six of the included studies were conducted in Ethiopia, 5 studies in Kenya, 4 studies each in Tanzania and Cameroon, and 2 studies each in Ghana, Uganda, and Sudan. Of the 68 included studies, one each was conducted in Botswana, Gambia, Lesotho, Mauritius, Mozambique, Seychelles, Togo, and Zimbabwe. Most (80.9\%) of the included studies were cross-sectional, and only one was an intervention trial. Of the 68 included studies, 53 reported on risk factors, 12 reported on morbidities, and 3 reported both risk factors and morbidities. We found no evidence in almost 60\% (28/47) of countries included in the World Health Organisation Africa region.

(Continued on next page)
\end{abstract}

\footnotetext{
* Correspondence: desmondkuupiel98@hotmail.com; KuupielD@ukzn.ac.za

${ }^{2}$ Research for Sustainable Development Consult, Sunyani, Ghana

${ }^{3}$ Department of Public Health Medicine, School of Nursing and Public Health,

University of KwaZulu-Natal, 2nd Floor George Campbell Building, Durban

4001, South Africa

Full list of author information is available at the end of the article
}

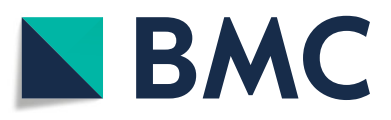

(c) The Author(s). 2020 Open Access This article is licensed under a Creative Commons Attribution 4.0 International License, which permits use, sharing, adaptation, distribution and reproduction in any medium or format, as long as you give appropriate credit to the original author(s) and the source, provide a link to the Creative Commons licence, and indicate if changes were made. The images or other third party material in this article are included in the article's Creative Commons licence, unless indicated otherwise in a credit line to the material. If material is not included in the article's Creative Commons licence and your intended use is not permitted by statutory regulation or exceeds the permitted use, you will need to obtain permission directly from the copyright holder. To view a copy of this licence, visit http://creativecommons.org/licenses/by/4.0/ The Creative Commons Public Domain Dedication waiver (http://creativecommons.org/publicdomain/zero/1.0/) applies to the data made available in this article, unless otherwise stated in a credit line to the data. 
(Continued from previous page)

Conclusion: This review findings suggest a paucity of literature on the risk factors of childhood obesity and morbidities in most SSA countries. Hence, there is the need to intensify research efforts, especially experimental study designs using innovative strategies to promote healthy lifestyle choices that will prevent or minimize the risks and health consequences of childhood obesity in SSA.

Keywords: Childhood, Obesity, Overweight, Risk factors, Morbidities, Sub-Saharan Africa

\section{Background}

The United Nations Sustainable Development Goal (SDG) target 2.2 enjoins the global community to end all forms of malnutrition by 2030, including overweight and obesity [1]. In spite of this objective, available evidence suggests an increasing trend of childhood overweight and obesity rates globally [2-4], with the fastest rise occurring in low-and middle-income countries (LMICs) $[5,6]$. Research has shown that the majority of overweight or obese children live in LMICs with over 30\% higher rates than that of high-income countries [7, 8]. In 2016, the World Health Organization (WHO) reported that over 340 million children and adolescents between the ages of 5 and 19, and 41 million under 5 years were either overweight or obese [9]. This rapidly increasing rate of obesity is considered one of the most serious public health challenges of the twenty-first century $[10,11]$, particularly in Sub-Saharan Africa (SSA) where health systems are weak and least prepared for the future complications arising from childhood obesity/overweight [5].

Childhood obesity has been linked with higher chances of adult obesity, premature death and disability [12]. Additionally, it is estimated that about 1.9 billion people globally will remain exposed to the poor health outcomes associated with overweight and obesity without the necessary commitment to fight this epidemic by national governments [13]. This problem could potentially result in the current generation of children having shorter life expectancy than their parents due to the increased burden of obesity-related diseases [14, 15]. Moreover, obese and overweight individuals have been reported to face higher levels of stigmatization [16], low self-worth and reduced health-related quality of life regardless of race or ethnicity [17].

Preventive strategies through risk factor identification, educational interventions and behavior change may be effective at reducing risk throughout the population, however, while the need for preventive action is increasingly recognized, policy implementation often occurs in a non-systematic, ad hoc manner [11]. Identifying and systematically presenting available evidence on the risk factors and morbidities associated with childhood obesity would help to tailor strategies that will be more evidence-based and sustainable. Although many studies have reported the rising burden of obesity, to the best of our knowledge, no study has comprehensively reviewed literature on the risk factors, morbidities and comorbidities associated with childhood obesity in SSA. In 2016, Fruhstorfer and colleagues conducted a systematic review, but their study was focused solely on socio-economic status and overweight or obesity among school-age children in SSA. Many other risk factors of childhood obesity/overweight may exist aside socio-economic factors. This study, therefore, systematically searched and described the evidence on the risk factors and morbidities associated with childhood obesity in SSA, identified gaps in the literature and made suggestions for health policy and future research.

\section{Methods}

We employed the Arksey and O'Malley methodological framework for scoping reviews 2005, Levac et al. 2010 recommendations, and the Joanna Briggs Institute guidelines [18-20] to conduct a systematic scoping review to answer the research question. A thorough description of the methods employed in this study has been reported earlier in the published protocol [21]. This study forms part of a larger review as described in the published protocol [21] however, this present study aimed at reporting evidence on risk factors and morbidities associated with childhood obesity/overweight in SSA. We followed the preferred reporting items for systematic reviews and meta-analysis extension for scoping reviews (PRISMA-ScR) to report this study results [22].

\section{Identifying the research question}

This scoping review sought to answer the following question: What is the evidence on the risk factors and morbidities associated with childhood obesity/overweight in SSA? To determine the eligibility of the review question for this study, the population, exposure, and outcome was used.

\section{Identifying relevant studies}

An exhaustive systematic keywords search was conducted in the following bibliographic databases PubMed, Google Scholar, Web of Science, and CINAHL for potentially eligible articles published between 2009 and June 2019. The database search was conducted between May 2019 and June 2019. The search strategy for 
relevant articles in the databases included a combination of keywords, Boolean terms (AND/OR), and Medical Subject Heading (MeSH) terms where possible. The electronic search strategy for this study is demonstrated in supplementary file 1. Publication language and study design limitations were removed whilst date was limited from 2000 to June 2019. A further search of the reference list of included studies was conducted for additional relevant articles. Supplementary file 1 shows the complete search strategy used in the databases.

\section{Eligibility criteria and study selection Eligibility criteria}

The investigators included articles reporting evidence on children aged from 2 to 18 years; articles reporting evidence of overweight (BMI $\geq 85$ th percentile) or obesity BMI is ( $\geq 95$ th percentile or $\geq 35 \mathrm{~kg} / \mathrm{m}^{2}$ ); and studies that used WHO reference criteria, Center for Disease Control and Prevention (United States) BMI growth charts, and International Obesity Task Force cut-offs; articles focused on risk factors and morbidities associated with childhood obesity/overweight; and studies conducted in SSA. It also included quantitative studies published between 2009 and 2019 and the publication language being English. However, studies that were conducted elsewhere outside SSA were excluded as well as studies published in French.

\section{Study selection}

FID and MAM conducted a comprehensive title search in the databases guided by the eligibility criteria in order to reduce selection bias. All potentially eligible articles were imported into Mendeley Desktop that was created for this review and duplicates removed. Once more, FID and MAM independently screened the abstracts and full texts using the inclusion and exclusion criteria. Discrepancies among the reviewers following abstract screening were resolved through discussions to build consensus. However, DK addressed the discrepancies between FID and MAM at the full-text screening stage. Subsequently, the inter-rater agreement (Cohen's kappa coefficient, $\mathrm{K}$ statistic) between the reviewers was calculated after the full-text screening using Stata version 14. An adapted PRISMA (Preferred Reporting Items for Systematic Reviews and Meta-Analysis) guideline was used to report the screening results [22].

\section{Charting data}

FID and DK independently extracted data using a piloted form designed in Google forms. Prior to the data extraction, FID and DK piloted the data extraction form with six of the included studies to ensure consistency and accuracy. Elements of the data extraction form included; author and date, study design, country of study, the study setting, sample size, age, sex, and outcomes reported (risk factors and morbidities).

\section{Collating and summarizing the results}

Thematic analysis was conducted following the data extraction process. The findings from the included studies were organised into the following themes: risk factors, and morbidities of childhood obesity/overweight. Subsequently, a summary of each theme was reported. Emerging themes were also reported.

\section{Results}

Our initial search of the databases produced 337,229 articles of which 959 satisfied the eligibility criteria following the title screening stage. This number was further reduced to 366 articles for the abstract screening after the deletion of 593 duplicates. An additional 293 articles were excluded after the abstract screening leaving 73 articles for the full text screening. Out of the 73 potentially relevant articles which were independently screen for the full text, 68 met the inclusion criteria and were included for data extraction (Fig. 1). Of the five articles that were excluded following the full text phase, four publications were in French even though their titles and abstracts were in English [23-26], and one reported evidence from elsewhere outside SSA [27].

\section{Characteristics of the included studies}

All 68 articles included in this study reported evidence on childhood obesity/overweight from a total of 19 countries in SSA including 2 multi-country studies. A greater proportion of the studies were from South Africa (27.9\%) and Nigeria (20.6\%), and one study each was conducted in eight countries (Botswana, Gambia, Lesotho, Mauritius, Mozambique, Seychelles, Togo and Zimbabwe). One of the multi-country studies involved Ghana and Uganda [28] and the other involved seven countries of which four (Benin, Ghana, Mauritania, and Malawi) are classified among SSA countries [28] (Fig. 2). We found no evidence in almost $60 \%$ (28/47) of countries included in the World Health Organisation Africa region.

The majority, 53 (77.9\%) of the studies reported evidence on risk factors of childhood obesity/overweight [27-79] while $12(17.7 \%)$ reported on associated morbidities [80-91], and 3 (4.4\%) presented evidence on both risk factors and morbidities [92-94]. Four of the included studies reported risk factors of obesity/overweight in children under 5 years $[54,59,67,77]$, and the remaining 64 reported risks factors of obesity/overweight in children and adolescents with varied ages. The minimum sample size of the included studies was 59 [79] and the maximum was 23,496 [28]. The included studies employed different quantitative and mixed study 


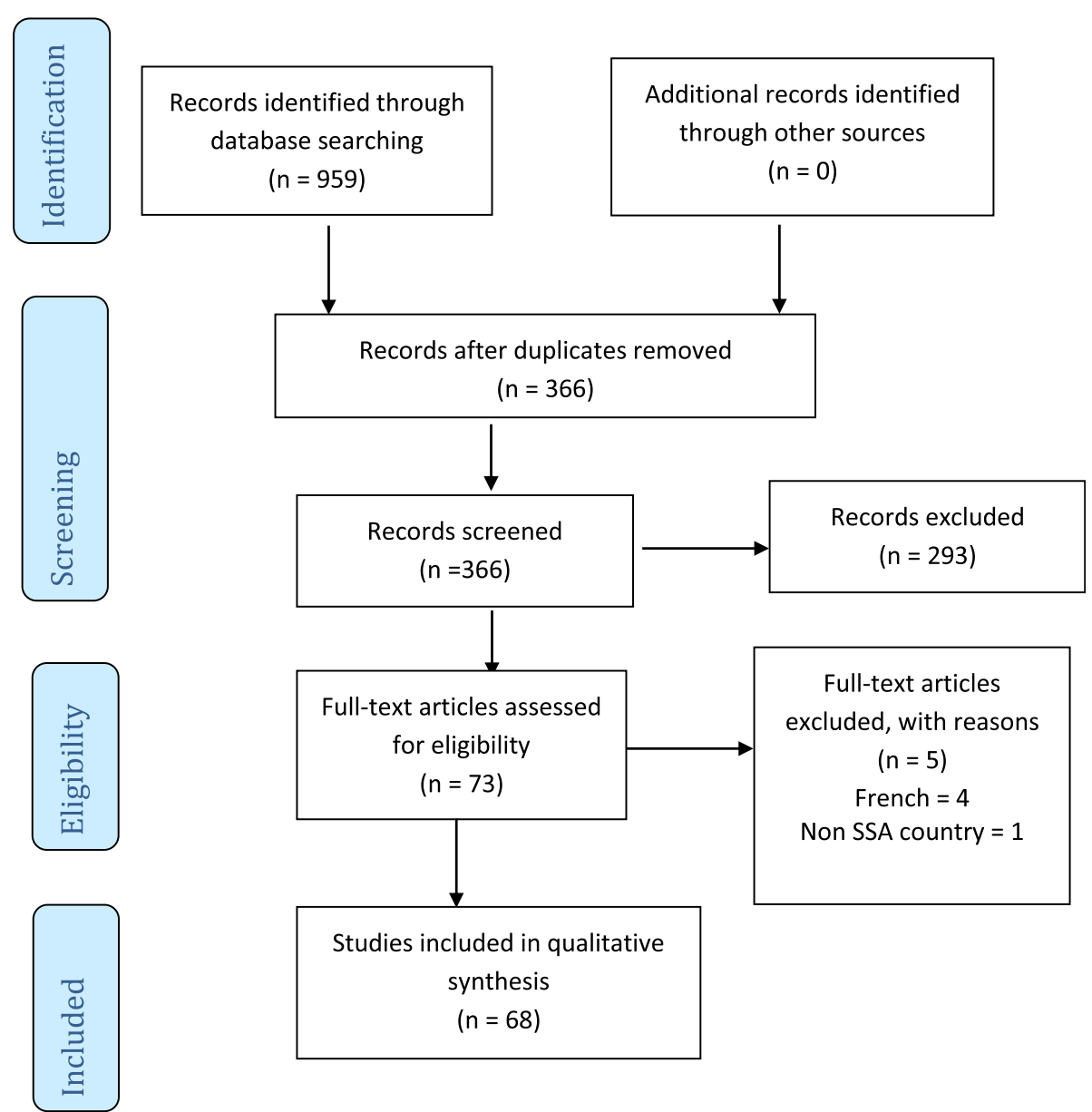

Fig. 1 PRISMA flow diagram showing results of literature search and study selection

designs including 55 (80.9\%) cross-sectional surveys [28, $30-33,36-38,40-60,62-66,68-71,73-76,78,80-82$, 84-95]; six (8.8\%) retrospective surveys using secondary data [27, 34, 35, 59, 67, 77]; four (5.9\%) longitudinal studies [29, 61, 72, 81]; one (1.5\%) Demographic Health Survey (41); one (1.5\%) intervention trial [80]; and one (1.5\%) case study [79]. Most of the included studies (67/ 68) participants involved both boys and girls, whilst one study involved only girls [79]. There was no study conducted with only male participants. Table 1 presents the characteristics of the included studies and outcomes reported.

\section{Study findings \\ Risk factors of childhood obesity/overweight}

Of the 68 included studies, the majority (56) reported evidence on the risk factors of childhood obesity/overweight in SSA. In all, the included studies reported 21 risk factors that were shown to have a positive association or relation with childhood obesity/overweight at their study settings. These risk factors are presented under the following sub-themes.
Economic status of parent Twenty-eight (28) of the 56 studies which presented evidence on risk factors found that higher economic status was associated with an increased risk of childhood obesity/overweight independently and in combination with other factors. In South Africa, seven studies conducted between 2011 and 2015 respectively established a relationship between economic status and obesity/overweight [29, 30, 32, 61, 72, 76]. Five studies from Ethiopia also reported on the relationship between higher parental economic status and childhood obesity/overweight risk [46-49, 51]. Also, four included studies conducted in Nigerian [36-38, 40], and two studies each in Cameroon [57, 58], Ghana [63, 64], and Tanzania $[60,94]$ found a correlation between obesity/ overweight and economic status. Furthermore, a study each conducted in Kenya, Sudan, Uganda, Botswana, the Gambia, and Zimbabwe also respectively reported that higher economic status was associated with increased risk of childhood obesity/overweight [55, 65, 67-69, 75].

Sex of the child Fourteen included studies presented evidence demonstrating the female sex as a risk factor 


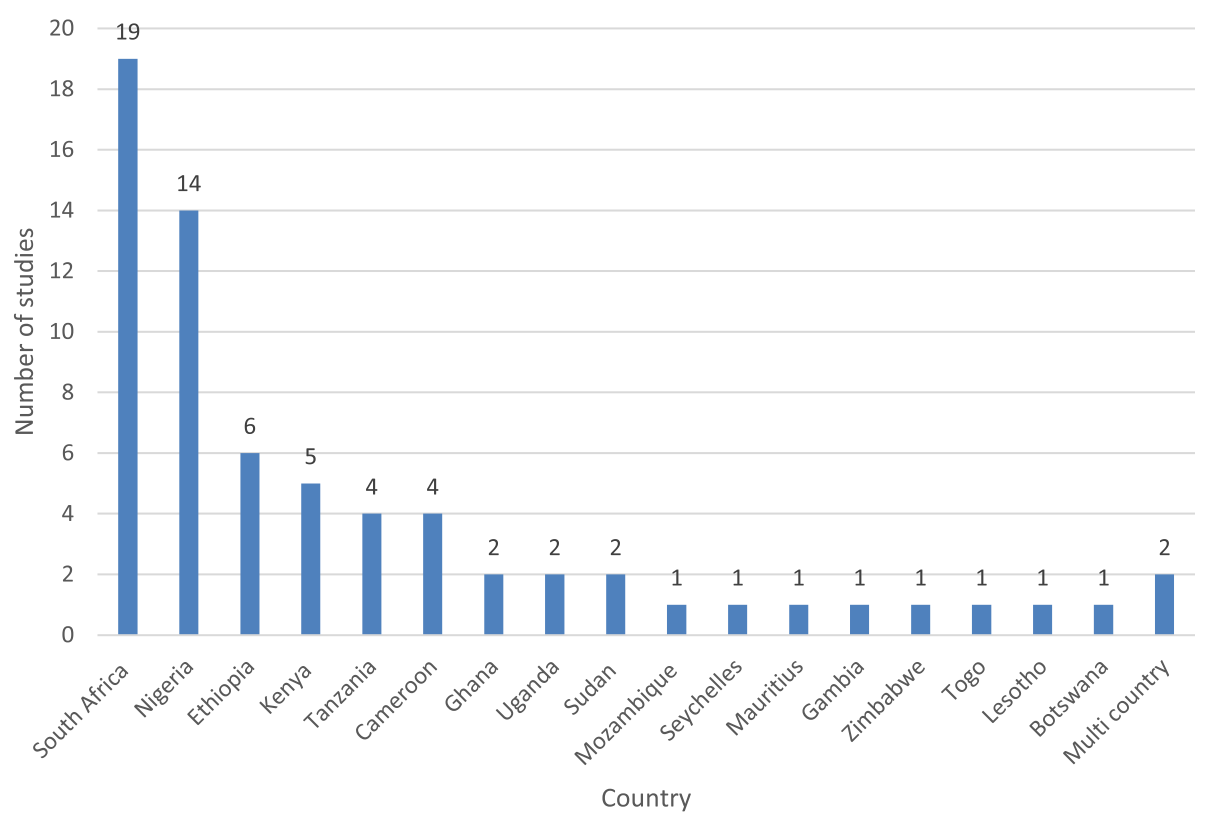

Fig. 2 Distribution of the included studies per countries

associated with child and adolescent obesity/overweight. Of these 14 studies, four studies each, conducted in South Africa [50, 78, 92, 93], and Nigeria [36, 40, 41, 45] reported that in both children and adolescents, there was a significantly higher prevalence of overweight and obesity among the girls than the boys. Two studies each, in Ethiopia [32, 33] and Tanzania [59, 60] also reported that female sex was significantly associated with childhood obesity and overweight. A study each in Ghana [64], and Uganda [66] respectively, further found that overweight/obesity was higher in females than males.

Urban residence Nine (9) studies reported evidence on the association between geographical settlement and childhood obesity/overweight [31, 32, 42, 52, 53, 67, 71, $75,91]$. In all the 9 studies, there was a higher risk of childhood obesity/overweight among urban dwellers than rural dwellers. A study in South Africa reported significantly higher rates of overweight/obesity among urban children and adolescents than their rural counterparts [31, 32]. Moreover, one study each from Nigeria [42], Ethiopia [52], Kenya [53], Tanzania [91], Uganda [67], Mauritius [71], and Zimbabwe [75] also presented evidence of higher obesity rates in urban children compared to rural children.

Consumption of highly refined/processed foods, snacks, and sweetened beverages Eight included studies reported evidence on the association between frequent consumption of processed foods, snacks, and sweetened beverages and the risk of developing obesity among children. In Nigeria, 3 studies [37, 43, 44] established a significant association between overweight and frequent consumption of snacks, soft drinks and refined highly processed foods. Two studies conducted in South Africa also reported an association between consumption of snacks/sweetened beverages and higher obesity rates among adolescents [61, 79]. A study each in Ethiopia, Cameroon, and Lesotho further reported a higher risk of obesity in relation to frequent snack and sweet foods consumption in their respective studies $[48,57,70]$.

Age Increasing age was found to be positively correlated with higher obesity/overweight rates especially among females. Two studies each in South Africa [50, 76], Nigeria [40, 45] and Tanzania [91, 94] all reported higher rates of obesity with increasing age, with adolescent females recording the highest rates. A study each in Ethiopia and Uganda also reported higher rates of obesity with increasing age of the child $[52,66]$.

Parental level of education Six studies reported that a higher level of parental education, especially maternal education, was positively associated with childhood obesity and overweight. Two studies in Kenya found that higher parental education was linked with a higher likelihood for a child to be overweight or obese $[39,55]$. In Ethiopia 2 studies also reported that a father's educational status and mother's educational status respectively were associated with childhood obesity [47, 48]. A study each in South Africa [78] and Nigeria [37] also found an 
Table 1 Characteristics of the included studies and outcomes reported

\begin{tabular}{|c|c|c|c|c|c|c|c|c|}
\hline No. & Author \& date & Study design & Country & Setting & Sample size & $\begin{array}{l}\text { Age range } \\
\text { (years) }\end{array}$ & Gender & $\begin{array}{l}\text { Outcome } \\
\text { reported }\end{array}$ \\
\hline 1 & Baumgartner et al. 2013 [80] & $\begin{array}{l}\text { Placebo-controlled, double- } \\
\text { blind intervention trial. }\end{array}$ & South Africa & Rural, urban & 321 & $6-11$ & Male, female & Morbidity \\
\hline 2 & Craig et al. 2016 [50] & Cross-sectional survey & South Africa & Rural & 1519 & $7-15$ & Male, female & Risk factors \\
\hline 3 & Feeley et al. 2013 [61] & Longitudinal study & South Africa & Urban & 1298 & $13-17$ & Male, female & Risk factors \\
\hline 4 & Ginsburg et al. 2013 [72] & Longitudinal study & South Africa & Urban & 1613 & 15 & Male, female & Risk factors \\
\hline 5 & Kimani-Murage et al. 2010 [92] & Cross-sectional survey & South Africa & Rural & 3511 & $1-20$ & Male female & $\begin{array}{l}\text { Risk factors, } \\
\text { morbidity }\end{array}$ \\
\hline 6 & Kimani-Murage et al. 2011 [76] & Cross-sectional survey & South Africa & Rural & 1848 & $10-20$ & Male, female & Risk factors \\
\hline 7 & Lesiapeto et al. 2016 [77] & $\begin{array}{l}\text { Retrospective survey } \\
\text { (Secondary data analysis) }\end{array}$ & South Africa & Rural & 2485 & $<5$ & Male, female & Risk factors \\
\hline 8 & Meko et al. 2015 [78] & Cross-sectional survey & South Africa & Urban & 415 & $13-15$ & Male, female & Risk factors \\
\hline 9 & Mokabane et al. 2014 [79] & Case study & South Africa & Peri-urban & 56 & $13-19$ & Female & Risk factors \\
\hline 10 & Munthali et al. 2016 [81] & Longitudinal study & South Africa & Urban & 1824 & $5-18$ & Male, female & Morbidity \\
\hline 11 & Negash et al. 2017 [93] & Cross-sectional survey & South Africa & Urban & 1559 & $7-18$ & Male, female & $\begin{array}{l}\text { Risk factor, } \\
\text { morbidity }\end{array}$ \\
\hline 12 & Pienaar 2015 [29] & Longitudinal study & South Africa & Rural, urban & 574 & $6-9$ & Male, female & Risk factors \\
\hline 13 & Pisa et al. 2015 [30] & Cross-sectional survey & South Africa & Rural & 388 & $11-15$ & Male, female & Risk factors \\
\hline 14 & Pretorius et al. 2019 [31] & Cross-sectional survey & South Africa & Rural, urban & 1785 & $6-12$ & Male, female & Risk factors \\
\hline 15 & Reddy et al. 2012 [32] & Cross-sectional survey & South Africa & Rural, urban & 4010 & Mean $=16.5$ & Male, female & Risk factors \\
\hline 16 & Sedibe et al. 2018 [33] & Cross-sectional survey & South Africa & Rural, urban & 3490 & $11-15$ & Male, female & Risk factors \\
\hline 17 & Steyn et al. 2011 [34] & $\begin{array}{l}\text { Retrospective survey } \\
\text { (Secondary data analysis) }\end{array}$ & South Africa & Rural, urban & 2469 & $1-9$ & Male, female & Risk factors \\
\hline 18 & Symington et al. 2016 [35] & $\begin{array}{l}\text { Retrospective survey } \\
\text { (Secondary data analysis) }\end{array}$ & South Africa & Rural, urban & 519 & $3-9$ & Male, female & Risk factors \\
\hline 19 & Zeelie et al. 2010 [84] & Cross-sectional survey & South Africa & Rural, Urban & 232 & $5-19$ & Male, female & Morbidity \\
\hline 20 & Adegoke et al. 2009 [36] & Cross-sectional survey & Nigeria & Semi-urban & 720 & $6-18$ & Male, female & Risk factors \\
\hline 21 & Adesina et al. 2012 [37] & Cross-sectional survey & Nigeria & Urban & 960 & $10-19$ & Male, female & Risk factors \\
\hline 22 & Akodu et al. 2012 [38] & Cross-sectional survey & Nigeria & Urban & 160 & $2-15$ & Male, female & Risk factors \\
\hline 23 & Ene-Obong et al. 2012 [40] & Cross-sectional survey & Nigeria & Urban & 1599 & $5-18$ & Male, female & Risk factors \\
\hline 24 & Maruf et al. 2013 [41] & Cross-sectional survey & Nigeria & Urban & 9014 & $2-18$ & Male, female & Risk factors \\
\hline 25 & Musa et al. 2012 [42] & Cross-sectional survey & Nigeria & Rural, urban & 3240 & $9-16$ & Male, female & Risk factors \\
\hline 26 & Nwaiwu et al. 2015 [85] & Cross-sectional survey & Nigeria & Not specified & 406 & $2-15$ & Male, female & Morbidity \\
\hline 27 & Oduwole et al. 2012 [86] & Cross-sectional survey & Nigeria & Urban & 885 & $9-18$ & Male, female & Morbidity \\
\hline 28 & Omisore et al. 2015 [87] & Cross-sectional survey & Nigeria & Not specified & 1000 & $10-19$ & Male, female & Morbidity \\
\hline 29 & Omuemu et al. 2010 [43] & Cross-sectional survey & Nigeria & Urban & 300 & $10-19$ & Male, female & Risk factors \\
\hline 30 & Opara et al. 2010 [44] & Cross-sectional survey & Nigeria & Rural, urban & 985 & $2.5-14$ & Male, female & Risk factors \\
\hline 31 & Senbanjo et al. 2010 [45] & Cross-sectional survey & Nigeria & Urban & 570 & $5-19$ & Male, female & Risk factors \\
\hline 32 & Senbanjo et al. 2012 [88] & Cross-sectional survey & Nigeria & Urban & 423 & $10-19$ & Male, female & Morbidity \\
\hline 33 & Uwaezuoke et al. 2016 [89] & Cross-sectional survey & Nigeria & Urban & 2419 & $10-19$ & Male, female & Morbidity \\
\hline 34 & Mekonnen et al. 2018 [46] & Cross-sectional survey & Ethiopia & Rural, urban & 634 & $6-12$ & Male, female & Risk factors \\
\hline 35 & Moges et al. 2018 [47] & Cross-sectional survey & Ethiopia & Urban & 1276 & $10-19$ & Male, female & Risk factors \\
\hline 36 & Sorrie et al. 2017 [48] & Cross-sectional survey & Ethiopia & Urban & 504 & $3-5$ & Male, female & Risk factors \\
\hline 37 & Tadesse et al. 2017 [49] & Cross-sectional survey & Ethiopia & Urban & 462 & $3-6$ & Male, female & Risk factors \\
\hline 38 & Teshome et al. 2013 [51] & Cross-sectional survey & Ethiopia & Urban & 559 & $10-19$ & Male, female & Risk factors \\
\hline 39 & Wakayo et al. 2016 [52] & Cross-sectional survey & Ethiopia & Rural, urban & 174 & $11-18$ & Male, female & Risk factors \\
\hline 40 & Adamo et al. 2011 [53] & Cross-sectional survey & Kenya & Rural, urban & 179 & $9-13$ & Male, female & Risk factors \\
\hline 41 & Gewa, 2010 [39] & DHS & Kenya & Rural, urban & 1495 & $3-5$ & Male, female & Risk factors \\
\hline
\end{tabular}


Table 1 Characteristics of the included studies and outcomes reported (Continued)

\begin{tabular}{|c|c|c|c|c|c|c|c|c|}
\hline No. & Author \& date & Study design & Country & Setting & Sample size & $\begin{array}{l}\text { Age range } \\
\text { (years) }\end{array}$ & Gender & $\begin{array}{l}\text { Outcome } \\
\text { reported }\end{array}$ \\
\hline 42 & Kimani-Murage et al. 2015 [54] & Cross-sectional survey & Kenya & Urban & 3335 & $<5$ & Male, female & Risk factors \\
\hline 43 & Muthuri et al. 2014 [55] & Cross-sectional survey & Kenya & Urban & 563 & $9-13$ & Male, female & Risk factors \\
\hline 44 & Wachira et al. 2018 [56] & Cross-sectional survey & Kenya & Urban & 563 & $9-11$ & Male, female & Risk factors \\
\hline 45 & Choukem et al. 2017 [57] & Cross-sectional Survey & Cameroon & Urban & 1343 & $3-13$ & Male, female & Risk factors \\
\hline 46 & Chedjou-Nono et al. 2017 [90] & Cross-sectional survey & Cameroon & urban & $\begin{array}{l}38 \text { cases: } \\
38 \text { controls }\end{array}$ & $3-17$ & Male, female & Morbidity \\
\hline 47 & Navti et al. 2014 [58] & Cross-sectional survey & Cameroon & Rural, urban & 557 & $5-12$ & Male, female & Risk factors \\
\hline 48 & Tchoubi et al. 2015 [59] & $\begin{array}{l}\text { Retrospective survey } \\
\text { (Secondary data analysis) }\end{array}$ & Cameroon & Rural, urban & 4518 & $<5$ & Male, female & Risk factors \\
\hline 49 & Mosha et al. 2010 [60] & Cross-sectional survey & Tanzania & Urban & 428 & $6-12$ & Male, female & Risk factors \\
\hline 50 & Muhihi et al. 2013 [94] & Cross-sectional survey & Tanzania & Rural, urban & 446 & $6-17$ & Male, female & $\begin{array}{l}\text { Risk factors, } \\
\text { morbidity }\end{array}$ \\
\hline 51 & Mushengezi et al. 2014 [91] & Cross-sectional survey & Tanzania & Urban & 582 & $12-19$ & Male, female & morbidity \\
\hline 52 & Mwaikambo et al. 2015 [62] & Cross-sectional survey & Tanzania & Urban & 1722 & $7-14$ & Male, female & Risk factors \\
\hline 53 & Adom et al. 2019 [63] & Cross-sectional survey & Ghana & Urban & 543 & $8-11$ & Male, female & Risk factors \\
\hline 54 & Mohammed et al. 2012 [64] & Cross-sectional survey & Ghana & Urban & 270 & $5-15$ & Male, female & Risk factors \\
\hline 55 & Nagwa et al. 2011 [65] & Cross-sectional survey & Sudan & Urban & 1138 & $10-18$ & Male, female & Risk factors \\
\hline 56 & Salman et al. 2011 [82] & Cross-sectional survey & Sudan & Urban & 304 & $6-12$ & Male, female & Morbidity \\
\hline 57 & Christoph et al. 2017 [66] & Cross-sectional survey & Uganda & Rural, urban & 148 & $11-16$ & Male, female & Risk factors \\
\hline 58 & Turi et al. 2013 [67] & $\begin{array}{l}\text { Retrospective survey } \\
\text { (Secondary data analysis) }\end{array}$ & Uganda & Rural, urban & 1099 & $<5$ & Male, female & Risk factors \\
\hline 59 & Wrotniak et al. 2012 [68] & Cross-sectional survey & Botswana & Rural, urban & 707 & $12-18$ & Male, female & Risk factors \\
\hline 60 & Juwara et al. 2016 [69] & Cross-sectional survey & Gambia & Urban & 960 & $13-15$ & Male, female & Risk factors \\
\hline 61 & Van den Berg et al. 2014 [70] & Cross-sectional survey & Lesotho & Urban & 221 & 16 & Male, female & Risk factors \\
\hline 62 & Caleyachetty et al. 2012 [71] & Cross-sectional survey & Mauritius & Rural, urban & 241 & $9-10$ & Male, female & Risk factors \\
\hline 63 & Dos Santos et al. 2015 [83] & Cross-sectional survey & Mozambique & Urban, suburban & 323 & $10-15$ & Male, female & Morbidity \\
\hline 64 & Bovet et al. 2010 [73] & Cross-sectional survey & Seychelles & Rural, urban & 8462 & $\begin{array}{l}\text { Mean ages; } \\
9.2,12.6 \text { and } \\
15.3 \text { years }\end{array}$ & Male, female & Risk factors \\
\hline 65 & Sagbo et al. 2018 [74] & Cross-sectional survey & Togo & Urban & 634 & $8-17$ & Male, female & Risk factors \\
\hline 66 & Kambondo et al. 2018 [75] & Cross-sectional survey & Zimbabwe & Rural, urban & 974 & $6-12$ & Male, female & Risk factors \\
\hline 67 & Peltzer et al. 2011 [27] & $\begin{array}{l}\text { Retrospective survey } \\
\text { (Secondary data analysis) }\end{array}$ & Ghana, Uganda & Not specified & 5613 & $13-15$ & Male, female & Risk factors \\
\hline 68 & Manyanga et al. 2014 [28] & Cross-sectional survey & $\begin{array}{l}\text { Benin, Ghana, } \\
\text { Mauritania, } \\
\text { Malawi }\end{array}$ & Not specified & 23,496 & $11-17$ & Male, female & Risk factors \\
\hline
\end{tabular}

association between childhood obesity and higher parental level of education.

Low level of physical activity (sedentary lifestyle) In six (6) of the included studies, two conducted in Ethiopia [47, 51], and one each from South Africa [79], Nigeria [43], Cameroon [57], and Togo [74], low levels of physical activity or sports were found to be associated to a higher risk of developing childhood obesity.

Attending private or public school Six included studies demonstrated evidence on the link between the type of school a child attends and the child's BMI. A study each in Nigeria, Ethiopia, Ghana, Botswana, Gambia, and Seychelles reported a higher prevalence of childhood overweight/obesity in private schools compared to public schools [44, 46, 63, 68, 69, 73].

Maternal obesity Six included studies revealed maternal obesity have a correlation with the risk of childhood obesity. Two studies in Kenya $[39,55]$, and a study each in South Africa [34], Nigeria [43], Cameroon [60], and Uganda [67], reported that overweight and obese parents, especially obese mothers, were more likely to have obese children. 
Screen time Six studies: 2 in Ethiopia [48, 51], and a study each in Nigeria [37], Sudan [62], Ghana [63], and Togo [74] reported found that children who spent two or more hours a day watching TV or playing/working on the computer were more likely to be overweight or obese.

Birth weight Three studies found a relationship between the birth weight of a child and the risk of developing obesity. Two studies in Cameroon $[58,59]$ and one in Kenya [39] found that children with high birth weight were more likely to develop obesity compared to normal birth-weight children.

Household size Three included studies that is, one each South Africa [50], Ethiopia [49], and Zimbabwe [75] reported that having fewer people less than 18 years in a household, family size $<5$, and having one child in a household respectively, were associated with a higher likelihood of overweight/obesity.

Stature Three studies also found a linkage between a child stature obesity/overweight. In South Africa, a study found that among children aged 3-9 years, stunting was associated with a high prevalence of obesity [35]. Similarly, a study in Kenya among children aged 3-5 years reported that stunting was associated with high odds of overweight and obesity [39]. Another study in Cameroon involving children aged 5 to 12 years reported that being tall was independently predictive of obesity [58].

Smoking, loneliness, vitamin D deficiency, and parental diabetes status Three studies further reported smoking, loneliness, and vitamin D deficiency as risks factors associated with childhood obesity/overweight. A study conducted among adolescents aged 13-15 years in Ghana and Uganda found that among girls, smoking cigarettes and loneliness and among boys, smoking cigarettes were associated with obesity [27]. An Ethiopian study in 2016 concluded that vitamin D deficiency was an independent predictor significantly associated with overweight and/or obesity among school adolescents from rural and urban settings in Ethiopia [52]. In Zimbabwe, a recent study reported that parental diabetes status was a significant risk factor of overweight/obesity [75].

\section{Morbidities and comorbidities associated with childhood obesity/overweight}

Fifteen (15) studies reported evidence on the morbidities and comorbidities associated with childhood obesity in SSA. Eight of the 15 (53.3\%) studies that presented evidence on morbidities reported on the association between childhood obesity and the risk of elevated blood pressure (BP). In Nigeria, a study reported that among
885 youth aged $9-18$ years, obesity significantly increased the risk of both systolic and diastolic BP in the hypertensive range, especially in older adolescents [86]. Still in Nigeria, two studies also found a higher prevalence of elevated $\mathrm{BP}$ among overweight/obese adolescents compared to their counterparts with normal BMI [88, 89]. A study in Nigeria further reported a positive association between obesity and elevated BP, especially obese females, in their study involving 1000 adolescents [87]. A study among Tanzanian children in 2013 [94] found that obese children had significantly higher systolic and diastolic BP. In 2014, another study in Tanzania reported that BMI and waist circumference were independently predictive of higher mean arterial pressure [91]. A longitudinal study in South Africa, measured BMI of 1824 children at ages 5 through 18 years and observed that early onset obesity/overweight was associated with increased risk of elevated BP in late adolescence [81]. In 2011, a similar study in Sudan found a high prevalence of overweight/obesity strongly associated with hypertension among primary school children in urban Sudan [82].

Also, three studies reported evidence on NCD comorbidities and childhood obesity/overweight. In South Africa, a study reported that overweight/obesity was associated with increased risk of hypertension, hypertriglyceridemia and low HDL cholesterol which constitute NCD comorbidities [93]. Moreover, Zeelie et al. study found that girls with a high body fat percentage had significantly higher BP, plasma insulin, and insulin resistance than girls with normal body fat percentage, indicating a risk of NCD [84]. A study among 406 Nigerian children aged 3 to 15 years, indicated that overweight and obese children had increased cardiovascular risk characterized by higher levels of total cholesterol and LDL cholesterol [85]. In 2010 study in South Africa found increased risk for metabolic disease associated with overweight/obesity among 3511 children, especially adolescent females [92]. In Cameroon, a study using 38 obese and 38 controls matched for age and sex found that, the obese children had higher risk of metabolic syndrome (dyslipidemia, high BP and type 2 diabetes mellitus) [90]. Furthermore, a study in 2015 reported a positive association between body weight and cardiometabolic risk among Mozambican adolescents [83]. Moreover, one study reported evidence on the association between childhood obesity and iron deficiency anaemia. Among South African children, a placebo-controlled, double-blind intervention trial reported that overweight/ obese children had a two-fold higher risk of remaining iron deficient after iron supplementation [80].

\section{Discussions}

This scoping review provided evidence on the risk factors and morbidities associated with childhood obesity/ 
overweight in SSA from published studies between January 2009 and July 2019. The results indicated that a total of 68 studies conducted in 19 SSA countries were published within the period. Majority of the studies were conducted in South Africa (27.9\%) and Nigeria (20.6\%). Most of the studies (53/68) provided evidence on risk factors, 12 on morbidities and 3 on both outcomes of interest. This study findings suggest limited studies on childhood obesity/overweight risk factors and morbidities in most parts of the region. The results further showed that most of the published studies were observational (80.9\% cross-sectional studies) with very limited intervention trials.

The study revealed that several factors independently and in combination were associated with childhood obesity/overweight risk and morbidity in SSA. Among the risk factors, high economic status was the most (28/ 68) reported with association with childhood obesity/ overweight, followed by female sex (15/68), urban residence (9/58), increasing age (8/68) and consumption of highly processed foods, snacks and sweetened beverages $(8 / 68)$. This supports findings from Fruhstofer et al. systematic review study in which children from the highest SES households had a 5.3 times higher risk of obesity than children from the lowest SES households [96]. However, Frushstofer and colleagues did not find a significant association between parental educational level and childhood obesity, in contrast to our findings where six of the studies reported an association. Overall, we showed that socioeconomic status, gender, age, parity, physical inactivity, and increased energy, fat, and sugar intake are powerful predictors of overweight and/or obesity. In a study involving adolescents in the US, Frederick et al. observed a decreasing trend in prevalence of obesity in high SES adolescents as opposed to an increase among low SES adolescents, which contrasts with findings from this study [97]. This observation may be explained in part by the fact that most developing countries are experiencing the negative effects of westernization and a nutritional transition, characterized by increased availability and consumption of highly processed, energy-dense foods, coupled with sedentary lifestyles [97-99].

The prevalence of obesity/overweight was also found to be higher in urban than rural children, in children attending private than public schools, and among girls than boys. In support of this finding, Bloom et al. explained that urban areas have easier access to highcalorie foods, over-reliance on public and private means of transport rather than walking, a rising scarcity of open spaces and parks for recreation, and availability of technological goods and services such as computers and televisions which promote sedentary lifestyle and contribute significantly to the greater burden of obesity in cities [97]. Again, Mokabane and colleagues found that girls in their study consumed significant quantities of snacks and beverages, spent a significant amount of time performing sedentary activities and very little time being physically active each day [30] which may explain the higher rates of obesity found in girls than boys. A study in Brazil by Rosaneli et al., found that obesity rates were higher in private than public schools, which agrees with findings from this study, however, boys in their study were more likely to be obese than girls [100]. Similar to findings of this study, increasing age, lack of physical activity, SES and maternal education were found to be potential risk factors of obesity among Iranian children by Mozaffari and colleague [79]. Parental BMI, especially maternal obesity was also found to be significantly associated with childhood obesity. This finding again agrees with that of Reuter et al., where maternal obesity was associated with a higher risk of childhood obesity in Brazil [101].

Among the associated morbidities identified, NCD, high blood pressure and metabolic disease were predominant. Elsewhere, studies have reported a number of obesity related health conditions in children including hypertension, type 2 diabetes, metabolic, cardiovascular and respiratory disorders [102-104]. Moreover, ElKarasky et al. found a close association between obesity and metabolic syndrome, insulin resistance and nonalcoholic fatty liver disease [105]. Our study findings also revealed an association between obesity and iron deficiency anaemia in children which confirms similar results by Hamza et al. who reported a correlation between obesity and iron deficiency anaemia [106].

\section{Implications for research}

Our study provides some recommendations for future research. We found that majority of the published studies in SSA were observational in nature. However, health promotion strategies, preventive measures and interventions are essential to help minimize the risks and consequences of childhood obesity. We, therefore, recommend more experimental study designs using interventions such as physical activity, diet, or educational intervention to facilitate policy decisions. Although SSA faces a rapid rise in obesity rates, this found no evidence from 28 SSA. Perhaps, this study either missed studies conducted in those countries or they are yet to be published. It is also possible no scientific study has been conducted yet on childhood obesity in those countries. Nonetheless, this finding demonstrates the need to scale up research on childhood obesity in SSA countries to guide policies and future research.

\section{Implications for practice}

Since children spend most of their time in school than many other environments [107], educational institutions, teachers and school authorities can play key roles in prevention of obesity/overweight and promotion of healthy 
lifestyles among school children through collaborative efforts with parents, NGOs and civil society groups. Health education programmes tailored for school children and adolescents should incorporate NCD risk factors modification, physical activity and nutritional education to help curb the childhood obesity pandemic. Additionally, SSA governments and the global food processing industry have a duty to ensure that children have access to healthy and nutritious food choices while cutting down on production and importation of highly processed, energy dense foods. Environmental and health policies that encourage active lifestyles and provide opportunities for recreation and sports should be formulated and implemented especially among the most vulnerable populations.

\section{Strengths and limitations}

We acknowledge the strengths and weaknesses inherent in this study. The search strategy employed was comprehensive and thorough enough in reviewing the existing literature from only peer-reviewed articles to address the research question. The study protocol was also published in a peer-reviewed journal [21]. Moreover, we followed the PRISMA extension for scoping reviews guidelines to ensure transparency in reporting this study. This study is arguably, the first study to systematically search, examine, and map evidence on the risk factors of childhood obesity/overweight and morbidities in SSA. This review was however limited to studies published in English, from January 2009 to July 2019 and within the geographical boundary of SSA. This could potentially exclude other relevant information not captured in the eligibility criteria of this study. The exclusion of four publications in French meant that we probably did not capture all relevant studies and the findings of this may not be generalized. Limited databases were searched for the relevant articles and probably further excluded some relevant studies. Nonetheless, this study has provided useful information to guide future research.

\section{Conclusion}

This study provided evidence on the risk factors and morbidities associated with childhood obesity/overweight in SSA. The findings from this study suggest limited published evidence on childhood obesity/overweight risk factors and morbidities in most SSA countries. Majority of the available evidence were from South Africa and Nigeria with few studies conducted in other parts of SSA. Therefore, more researches are needed to inform policy going forward, particularly experimental study designs using innovative strategies to promote healthy lifestyle choices that will prevent or minimize the risks and health consequences of childhood obesity/overweight in SSA. We also recommended more collaborative efforts between schools, parents, health and educational policy makers and other stakeholders in promoting healthy lifestyle choices and preventive strategies among young people that will help minimize the risks and health consequences of childhood obesity in SSA.

\section{Supplementary information}

Supplementary information accompanies this paper at https://doi.org/10. 1186/s40795-020-00364-5.

Additional file 1. Electronic databases search results for title screening.

\section{Abbreviations}

BMI: Body Mass Index; LIC: Low-Income Country; LMIC: Lower-Middle-Income Country; NCD: Non-Communicable Disease; SSA: Sub-Saharan Africa; UMIC: Upper-Middle-Income Country; WHO: World Health Organization

\section{Acknowledgements}

We are thankful to the Catholic University College of Ghana, Fiapre and the University of KwaZulu-Natal, Durban for providing us with essential resources to complete this review.

Adherence to national and international regulations Not applicable.

Authors' contributions

FID conceptualized the study and wrote the manuscript. FID, MA-M and MY contributed to the abstract and full-text screening. DK contributed to the full-text screening. FID and DK performed the quality appraisal of the included studies. VB and DK critically reviewed the manuscript and made revisions. All the authors approved the final draft.

Funding

No funding was obtained for this study.

\section{Availability of data and materials}

The data supporting the conclusion of this paper are available through the detailed reference list. No original datasets are presented since this was a review of previously existing literature.

Ethics approval and consent to participate

This study is a systematic scoping review that relied solely on existing literature. Hence, ethical approval was not required since there were no human participants.

Consent for publication

Not applicable.

Competing interests

The authors declared no competing interests.

\section{Author details}

${ }^{1}$ Department of Public Health, Faculty of Health and Allied Sciences, Catholic University College of Ghana, Fiapre, Sunyani, Ghana. ${ }^{2}$ Research for Sustainable Development Consult, Sunyani, Ghana. ${ }^{3}$ Department of Public Health Medicine, School of Nursing and Public Health, University of KwaZulu-Natal, 2nd Floor George Campbell Building, Durban 4001, South Africa.

Received: 30 March 2020 Accepted: 24 July 2020

Published online: 01 September 2020

\section{References}

1. World Health Organization. World Health Statistics 2018: monitoring health for the SDGs, sustainable development goals [Internet], vol. 15. Geneva: WHO; 2018. p. 2017-9. Available from: https://www.uam.es/gruposinv/ meva/publicacionesjesus/capitulos_espanyol_jesus/2005 motivacionparaelaprendizajePerspectivaalumnos.pdf\%0A https://www. 
researchgate.net/profile/Juan_Aparicio7/publication/253571379_Los_ estudios_sobre_el_cambio_conceptual_.

2. Apovian CM. Obesity: definition, comorbidities, causes, and burden. Am J Manag Care. 2016;22(7 Suppl):s176-85 [cited 2019 Mar 18] Available from: http://www.ncbi.nlm.nih.gov/pubmed/27356115.

3. Afshin A, Forouzanfar MH, Reitsma MB, Sur P, Estep K, Lee A, et al. GBD 2015 Obesity Collaborators: health effects of overweight and obesity in 195 Countries over 25 Years. N Engl J Med. 2017;377(1):13-27 [cited 2019 May 6] Available from: http://www.ncbi.nlm.nih.gov/pubmed/28604169.

4. GBD 2015 Eastern Mediterranean Region Obesity Collaborators. Burden of obesity in the Eastern Mediterranean Region: findings from the Global Burden of Disease 2015 study. Int J Public Health. 2018;63(Suppl 1):165-76. [cited 2019 May 3]. https://doi.org/10.1007/s00038-017-1002-5.

5. Bollyky BTJ, Templin T, Cohen M, Dieleman JL. Lower-income countries that face the most rapid shift in noncommunicable disease burden are also the least prepared. Health Aff (Millwood). 2017;11(11):1866-75.

6. Moore S, Hall JN, Harper S, Lynch JW. Global and national socioeconomic disparities in obesity, overweight, and underweight status. J Obes. 2010; 2010.

7. WHO. Consideration of the evidence on childhood obesity for the Commission on ending childhood obesity report of the Ad hoc Working Group on science and evidence for ending childhood obesity [Internet]. Geneva: WHO; 2016. [cited 2019 May 3]. Available from: http://www.who.int.

8. Rossouw HA, Grant CC, Viljoen M. Overweight and obesity in children and adolescents: The South African problem. S Afr J Sci. 2012;108(5-6):31-7 [cited 2019 May 20] Available from: http://www.scielo.org.za/scielo. php?script=sci_arttext\&pid=S0038-23532012000300011.

9. WHO. Obesity and overweight. Geneva: WHO; 2018.

10. Papatesta E-M, lacovidou N, St PM. Breastfeeding reduces the risk of obesity in childhood and adolescence. J Pediatr Neonatal Individ Med. 2013;2(2): 20206 Available from: www.jpnim.com.

11. WHO. Population-based prevention strategies for childhood obesity. Report of a WHO forum and technical meeting. Geneva: WHO; 2009.

12. W.H.O. WHO media centre obesity and overweight fact sheet; 2017. p. 3-7. Available from: http://www.who.int/mediacentre/factsheets/fs311/en/.

13. World Health Organization. Global NCD target halt the rise in obesity; 2015. p. 2015-6.

14. Lasserre A, Chiolero A, Paccaud FM, Bovet P. Worldwide trends in childhood obesity. Swiss Med Wkly. 2007;137:16-9 (June 2014) Available from: http:// www.scopus.com/inward/record.url?eid=2-s2.0-33947533100\&partnerlD= 40\&md5=5da1df8420cbaeb87fea63fe2570e79a.

15. Swinburn BA, Sacks G, Hall KD, McPherson K, Finegood DT, Moodie ML, et al. The global obesity pandemic: shaped by global drivers and local environments. Lancet. 2011;378(9793):804-14. https://doi.org/10.1016/501406736(11)60813-1.

16. Kumah DB, Akuffo KO, Abaka-Cann JE, Affram DE, Osae EA. Prevalence of overweight and obesity among students in the Kumasi Metropolis. J Nutr Metab. 2015;2015:1-4 [cited 2019 May 20] Available from: https://www. hindawi.com/journals/jnme/2015/613207/abs/.

17. Wallander UL, Kerbawy S, Toomey S, Lowry R, Elliott MN, Escobar-Chaves SL, et al. Is obesity associated with reduced health-related quality of life in Latino, black and white children in the community? Int J Obes. 2013;37(7): 920-5. https://doi.org/10.1038/ijo.2013.31.

18. Arksey H, Malley LO. Scoping studies: towards a methodological framework. Int J Soc Res Methodol. 2005;8:19-32.

19. Levac D, Colquhoun H, O'Brien KK. Scoping studies: advancing the methodology. Implement Sci. 2010;5(1):69 [cited 2019 Mar 23] Available from: http://www.ncbi.nlm.nih.gov/pubmed/20854677.

20. The Joanna Briggs Institute. The Joanna Briggs Institute Reviewers' Manual 2015: methodology for JBI scoping reviews. Adelaide: Joanne Briggs Inst; 2015. p. 1-24. Available from: http://joannabriggs.org/assets/docs/sumari/ ReviewersManual_Mixed-Methods-Review-Methods-2014-ch1.pdf.

21. Danquah FI, Yeboah M, Bawuntuo V, Kuupiel D. Mapping evidence on the burden and distribution of childhood obesity in Sub- Saharan Africa : a systematic scoping review protocol. BMC Nutr. 2019.

22. Moher D, Liberati A, Tetzlaff J AD. PRISMA 2009 flow diagram. 2009;6: 1000097.

23. Koueta F, Dao L, Dao F, Djekompte S, Sawadogo J, Diarra YE, et al. Factors associated with overweight and obesity among Ouagadougou students (Burkina Faso). Sante. 2011;21(4):227-31 [cited 2019 May 19] Available from: http://www.ncbi.nlm.nih.gov/pubmed/22407248.
24. Kramoh KE, N'goran YNK, Aké-Traboulsi E, Boka BC, Harding DE, Koffi DBJ, et al. Prevalence of obesity in school children in Ivory Coast. Ann Cardiol Angeiol. 2012;61(3):145-9 [cited 2019 May 19] Available from: https:// linkinghub.elsevier.com/retrieve/pii/S0003392812000583.

25. Oumar Bâ H, Menta I, Camara Y, Doumbia PS, Diarra MB. Overweight and obesity in the general population of 5-19 years in urban Bamako (Mali). Pan Afr Med J. 2014;19:351 [cited 2019 May 19] Available from: http://www.ncbi. nlm.nih.gov/pubmed/25932064.

26. Rees A, Thomas N, Brophy S, Knox G, Williams R. Cross sectional study of childhood obesity and prevalence of risk factors for cardiovascular disease and diabetes in children aged 11-13. BMC Public Health. 2009;9(1):86. [cited 2019 May 20]. https://doi.org/10.1186/1471-2458-9-86.

27. Peltzer K, Pengpid S. Overweight and obesity and associated factors among school-aged adolescents in Ghana and Uganda. Int J Environ Res Public Health. 2011;8(10):3859-70 [cited 2019 May 19] Available from: http://www. mdpi.com/1660-4601/8/10/3859.

28. Manyanga T, El-Sayed H, Doku DT, Randall JR. The prevalence of underweight, overweight, obesity and associated risk factors among schoolgoing adolescents in seven African countries. BMC Public Health. 2014;14(1): 887. https://doi.org/10.1186/1471-2458-14-887 [cited 2019 May 20].

29. Pienaar AE. Prevalence of overweight and obesity among primary school children in a developing country: NW-CHILD longitudinal data of 6-9-yr-old children in South Africa. BMC Obes. 2015;2(1). https://doi.org/10.1186/ s40608-014-0030-4 [cited 2019 May 20].

30. Pisa PT, Pedro TM, Kahn K, Tollman SM, Pettifor JM, Norris SA. Nutrient patterns and their association with socio-demographic, lifestyle factors and obesity risk in rural South African adolescents. Nutrients. 2015;7(5):3464-82 [cited 2019 May 19]. Available from: http://www.mdpi.com/2072-6643/ $7 / 5 / 3464$

31. Pretorius SS, Neophytou N, Watson ED. Anthropometric profiles of 8-11 year old children from a low-income setting in South Africa. BMC Public Health. 2019;19(1):314. https://doi.org/10.1186/s12889-019-6530-x [cited 2019 May 19].

32. Reddy SP, Resnicow K, James S, Funani IN, Kambaran NS, Omardien RG, et al. Rapid increases in overweight and obesity among South African adolescents: comparison of data from the South African National Youth Risk Behaviour Survey in 2002 and 2008. Am J Public Health. 2012;102(2):262-8. https://doi.org/10.2105/AJPH.2011.300222 [cited 2019 May 19].

33. Sedibe MH, Pisa PT, Feeley AB, Pedro TM, Kahn K, Norris SA. Dietary habits and eating practices and their association with overweight and obesity in rural and urban black South African adolescents. Nutrient. 2018;10(2):145 [cited 2019 May 19]. Available from: http://www.mdpi.com/2072-6643/1 $0 / 2 / 145$.

34. Steyn HNP, Labadarios BD, Nel SJ, Kruger HS, Maunder E. What is the nutritional status of children of obese mothers in South Africa? Nutrition. 2011;27(9):904-11. https://doi.org/10.1016/j.nut.2010.10.007 [cited 2019 May 19] Available from: https://linkinghub.elsevier.com/retrieve/pii/S089990071 0003485.

35. Symington EA, Gericke GJ, Nel JH, Labadarios D. The relationship between stunting and overweight among children from South Africa: secondary analysis of the national food consumption survey - Fortification baseline I. S Afr Med J. 2016;106(1):65-9 [cited 2019 May 20]. Available from: https:// www.ajol.info/index.php/samj/article/view/131158.

36. Adegoke SA, Olowu WA, Adeodu OO, Elusiyan JB, Dedeke IO. Prevalence of overweight and obesity among children in lle-ife, south-western Nigeria. West Afr J Med. 2009;28(4):216-21 [cited 2019 May 20]. Available from: http://www.ncbi.nlm.nih.gov/pubmed/20425735

37. Adesina AF, Peterside O, Anochie I, Akani NA. Weight status of adolescents in secondary schools in port Harcourt using Body Mass Index (BMI). Ital J Pediatr. 2012;38(1):31. https://doi.org/10.1186/1824-7288-38-31 [cited 2019 May 19].

38. Akodu SO, Diaku-Akinwumi IN, Njokanma OF. Obesity--does it occur in Nigerian children with sickle cell anemia. Pediatr Hematol Oncol. 2012;29(4): 358-64. https://doi.org/10.3109/08880018.2012.680682 [cited 2019 May 19].

39. Gewa CA. Childhood overweight and obesity among Kenyan pre-school children: association with maternal and early child nutritional factors. Public Health Nutr. 2010;13(4):496-503 [cited 2019 May 19]. Available from: https:// www.cambridge.org/core/product/identifier/S136898000999187X/type/ journal_article.

40. Ene-Obong H, Ibeanu V, Onuoha N, Ejekwu A. Prevalence of overweight, obesity, and thinness among urban school-aged children and adolescents 
in southern Nigeria. Food Nutr Bull. 2012;33(4):242-50 [cited 2019 May 19]. Available from: http://www.ncbi.nlm.nih.gov/pubmed/23424890.

41. Maruf FA, Aronu U, Chukwuegbu K, Aronu AE. Influence of gender on prevalence of overweight and obesity in Nigerian schoolchildren and adolescents. Tanzan J Health Res. 2013;15(4):247-51 [cited 2019 May 19]. Available from: http://www.ncbi.nlm.nih.gov/pubmed/26591700.

42. Musa DI, Toriola AL, Monyeki MA, Lawal B. Prevalence of childhood and adolescent overweight and obesity in Benue State, Nigeria. Trop Med Int Health. 2012;17(11):1369-75. https://doi.org/10.1111/j.1365-3156.2012.03083. x [cited 2019 May 20].

43. Omuemu VO, Omuemu CE. The prevalence of overweight and its risk factors among adolescents in an urban city in Edo State. Niger J Clin Pract. 2010;13(2):128-33 [cited 2019 May 19]. Available from: http://www.ncbi.nlm. nih.gov/pubmed/20499742.

44. Opara D, Ikpeme E, Ekanem U. Prevalence of stunting, underweight and obesity school aged children in Uyo, Nigeria. Pak J Nutr. 2010;9(5):459-66 [cited 2019 May 20]. Available from: http://docsdrive.com/pdfs/ansinet/pjn/2 010/459-466.pdf

45. Senbanjo IO, Oshikoya KA. Physical activity and body mass index of school children and adolescents in Abeokuta, Southwest Nigeria. World J Pediatr. 2010; 6(3):217-22. https:/doi.org/10.1007/s12519-010-0209-9 [cited 2019 May 19].

46. Mekonnen T, Tariku A, Abebe SM. Overweight/obesity among school aged children in Bahir Dar City: cross sectional study. Ital J Pediatr. 2018:44(1):17. https://doi.org/10.1186/s13052-018-0452-6 [cited 2019 May 19].

47. Moges T, Gebremichael B, Shiferaw S, Yirgu R. Is inadequate play area in schools associated with overweight among students in Addis Ababa, Ethiopia? A comparative cross-sectional study. Epidemiol Health. 2018;40: e2018017. https://doi.org/10.4178/epih.e2018017 [cited 2019 May 19].

48. Sorrie MB, Yesuf ME, GebreMichael TG. Overweight/Obesity and associated factors among preschool children in Gondar City, Northwest Ethiopia: a cross-sectional study. PLoS One. 2017;12(8):e0182511. https://doi.org/10. 1371/journal.pone.0182511 [cited 2019 May 19].

49. Tadesse Y, Derso T, Alene KA, Wassie MM. Prevalence and factors associated with overweight and obesity among private kindergarten school children in Bahirdar Town, Northwest Ethiopia: cross-sectional study. BMC Res Notes. 2017; 10(1):22. https://doi.org/10.1186/s13104-016-2308-8 [cited 2019 May 19].

50. Craig E, Reilly JJ, Bland R. Risk factors for overweight and overfatness in rural South African children and adolescents. J Public Health. 2016;38(1):24-33. https://doi.org/10.1093/pubmed/fdv016 [cited 2019 May 19].

51. Teshome T, Singh P, Moges D. Prevalence and associated factors of overweight and obesity among high school adolescents in urban communities of Hawassa, Southern Ethiopia. Curr Res Nutr Food Sci J. 2013; 1(1):23-36 [cited 2019 May 20] Available from: http://www. foodandnutritionjournal.org/volume1 number1/prevalence-and-associatedfactors-of-overweight-and-obesity-among-high-school-adolescents-in-urbancommunities-of-hawassa-southern-ethiopia/.

52. Wakayo T, Whiting SJ, Belachew T. Vitamin D deficiency is associated with overweight and/or obesity among schoolchildren in Central Ethiopia: a cross-sectional study. Nutrients. 2016;8(4):190 [cited 2019 May 19] Available from: http://www.mdpi.com/2072-6643/8/4/190.

53. Adamo KB, Sheel AW, Onywera V, Waudo J, Boit M, Tremblay MS. Child obesity and fitness levels among Kenyan and Canadian children from urban and rural environments: A KIDS-CAN Research Alliance Study. Int J Pediatr Obes. 2011;6(2-2):e225-32. https://doi.org/10.3109/17477166.2010.543683 [cited 2019 May 19].

54. Kimani-Murage EW, Muthuri SK, Oti SO, Mutua MK, van de Vijver S, Kyobutungi C. Evidence of a double burden of malnutrition in urban poor settings in Nairobi, Kenya. PLoS One. 2015;10(6):e0129943. https://doi.org/10. 1371/journal.pone.0129943 [cited 2019 May 19].

55. Muthuri SK, Wachira L-JM, Onywera VO, Tremblay MS. Correlates of objectively measured overweight/obesity and physical activity in Kenyan school children: results from ISCOLE-Kenya. BMC Public Health. 2014;14(1): 436. https://doi.org/10.1186/1471-2458-14-436 [cited 2019 May 19].

56. Wachira L-JM, Muthuri SK, Ochola SA, Onywera VO, Tremblay MS. Screenbased sedentary behaviour and adiposity among school children: Results from International Study of Childhood Obesity, Lifestyle and the Environment (ISCOLE) - Kenya. PLoS One. 2018;13(6):e0199790. https://doi. org/10.1371/journal.pone.0199790 [cited 2019 May 19].

57. Choukem S-P, Kamdeu-Chedeu J, Leary SD, Mboue-Djieka Y, Nebongo DN, Akazong C, et al. Overweight and obesity in children aged 3-13 years in urban Cameroon: a cross-sectional study of prevalence and association with socio-economic status. BMC Obes. 2017;4(1):7. https://doi.org/10.1186/ s40608-017-0146-4 [cited 2019 May 19].

58. Navti LK, Ferrari U, Tange E, Bechtold-Dalla Pozza S, Parhofer KG. Contribution of socioeconomic status, stature and birth weight to obesity in Sub-Saharan Africa: cross-sectional data from primary school-age children in Cameroon. BMC Public Health. 2014;14(1):320. https://doi.org/10.1186/14712458-14-320 [cited 2019 May 19].

59. Tchoubi S, Sobngwi-Tambekou J, Noubiap JJN, Asangbeh SL, Nkoum BA, Sobngwi E. Prevalence and risk factors of overweight and obesity among children aged 6-59 months in Cameroon: a multistage, stratified cluster sampling nationwide survey. PLoS One. 2015;10(12):e0143215. https://doi. org/10.1371/journal.pone.0143215 [cited 2019 May 20].

60. Mosha TC, Fungo S. Prevalence of overweight and obesity among children. Tanzan J Health Res. 2010;12(1):6-16 [cited 2019 May 19] Available from: http://www.ncbi.nlm.nih.gov/pubmed/20737824.

61. Feeley AB, Musenge E, Pettifor JM, Norris SA. Investigation into longitudinal dietary behaviours and household socio-economic indicators and their association with BMI Z-score and fat mass in South African adolescents: the Birth to Twenty (Bt20) cohort. Public Health Nutr. 2013;16(4):693-703 [cited 2019 May 20] Available from: https://www.cambridge.org/core/journals/ public-health-nutrition/article/investigation-into-longitudinal-dietarybehaviours-and-household-socioeconomic-indicators-and-their-associationwith-bmi-zscore-and-fat-mass-in-south-african-adolescents-the-birth-to-.

62. Mwaikambo SA, Leyna GH, Killewo J, Simba A, Puoane T. Why are primary school children overweight and obese? A cross sectional study undertaken in Kinondoni district, Dar-es-salaam. BMC Public Health. 2015;15(1):1269 Available from: http://www.biomedcentral.com/1471-2458/15/1269.

63. Adom T, De Villiers A, Puoane T, Kengne AP. Prevalence and correlates of overweight and obesity among school children in an urban district in Ghana. BMC Obes. 2019;6(1):14. https://doi.org/10.1186/s40608-019-0234-8 [cited 2019 May 19].

64. Mohammed H, Vuvor F. Prevalence of childhood overweight/obesity in basic school in Accra. Ghana Med J. 2012;46(3):124-7 [cited 2019 May 19] Available from: http://www.ncbi.n/m.nih.gov/pubmed/23661824.

65. Nagwa MA, Elhussein AM, Azza M, Abdulhadi NH. Alarming high prevalence of overweight/obesity among Sudanese children. Eur J Clin Nutr. 2011;65(3): 409-11 [cited 2019 May 19] Available from: http:/www.nature.com/articles/ ejcn2010253.

66. Christoph MJ, Grigsby-Toussaint DS, Baingana R, Ntambi JM. Physical activity, sleep, and BMl percentile in rural and urban Ugandan Youth. Ann Glob Heal. 2017;83(2):311-9. https://doi.org/10.1016/j.aogh.2017.04.005/ [cited 2019 May 19].

67. Turi KN, Christoph MJ, Grigsby-Toussaint DS. Spatial distribution of underweight, overweight and obesity among women and children: results from the 2011 Uganda Demographic and Health Survey. Int J Environ Res Public Health. 2013;10(10):4967-81 [cited 2019 May 19] Available from: http://www.mdpi.com/1660-4601/10/10/4967.

68. Wrotniak BH, Malete L, Maruapula SD, Jackson J, Shaibu S, Ratcliffe S, et al. Association between socioeconomic status indicators and obesity in adolescent students in Botswana, an African country in rapid nutrition transition. Pediatr Obes. 2012;7(2):e9-13. https://doi.org/10.1111/j.2047-6310. 2011.00023.x [cited 2019 May 19].

69. Juwara A, Huang N, Chien L-Y, Chen H-J. Stunting and weight statuses of adolescents differ between public and private schools in urban Gambia. Int J Public Health. 2016;61(6):717-26. https://doi.org/10.1007/s00038-016-08366 [cited 2019 May 19].

70. van den Berg VL, Seheri L, Raubenheimer J. Body mass index of 16-year olds in urban Maseru, Lesotho. Afr J Prim Heal Care Fam Med. 2014;6(1):E114 [cited 2019 May 19] Available from: https://phcfm.org/index.php/phcfm/ article/view/618.

71. Caleyachetty R, Rudnicka AR, Echouffo-Tcheugui JB, Siegel KR, Richards N, Whincup PH. Prevalence of overweight, obesity and thinness in 9-10 year old children in Mauritius. Glob Health. 2012;8(1):28. https:/doi.org/10.1186/ 1744-8603-8-28 [cited 2019 May 20].

72. Ginsburg C, Griffiths PL, Richter LM, Norris SA. Residential mobility, socioeconomic context and body mass index in a cohort of urban South African adolescents. Health Place. 2013;19(1):99-107 [cited 2019 May 20] Available from: https:/linkinghub.elsevier.com/retrieve/pii/S1353829212001827.

73. Bovet P, Chiolero A, Madeleine G, Paccaud F. Prevalence of overweight and underweight in public and private schools in the Seychelles 2010; (Febr 2009):274-8. 
74. Sagbo H, Ekouevi DK, Ranjandriarison DT, Niangoran S, Bakai TA, Afanvi A, et al. Prevalence and factors associated with overweight and obesity among children from primary schools in urban areas of Lomé, Togo. Public Health Nutr. 2018;21(6):1048-56 [cited 2019 May 19] Available from: https:// www.cambridge.org/core/product/identifier/S1368980017003664/type/ journal_article.

75. Kambondo G, Sartorius B. Risk factors for obesity and overfat among primary school children in Mashonaland West Province, Zimbabwe. Int Environ Res Public Health. 2018;15(2):249 [cited 2019 May 19] Available from: http://www.mdpi.com/1660-4601/15/2/249.

76. Kimani-Murage EW, Kahn K, Pettifor JM, Tollman SM, Klipstein-Grobusch K, Norris SA. Predictors of adolescent weight status and central obesity in rural South Africa. Public Health Nutr. 2011;14(6):1114-22 [cited 2019 May 19] Available from: https://www.cambridge.org/core/product/identifier/S136 8980011000139/type/journal_article.

77. Lesiapeto M, Smuts C, Hanekom S, Du Plessis J, Faber M. Risk factors of poor anthropometric status in children under five years of age living in rural districts of the Eastern Cape and KwaZulu-Natal provinces, South Africa. S Afr J Clin Nutr. 2016;23(4):202-7 [cited 2019 May 20] Available from: https://www.ajol.info/index.php/sajcn/article/view/63118.

78. Meko LNM, Slabber-Stretch M, Walsh CM, Kruger SH, Nel M. School environment, socioeconomic status and weight of children in Bloemfontein, South Africa. Afr J Prim Heal Care Fam Med. 2015;7(1) [cited 2019 May 19] Available from: https://phcfm.org/index.php/phcfm/article/view/751.

79. Mokabane MN, Mashao MM, van Staden M, Potgieter MJ, Potgieter A. Low levels of physical activity in female adolescents cause overweight and obesity: are our schools failing our children? S Afr Med J. 2014;104(10):665 [cited 2019 May 19] Available from: http://www.samj.org.za/index.php/samj/ article/view/8577.

80. Baumgartner J, Smuts CM, Aeberli I, Malan L, Tjalsma H, Zimmermann MB. Overweight impairs efficacy of iron supplementation in iron-deficient South African children: a randomized controlled intervention. Int J Obes. 2013; 37(1):24-30. https://doi.org/10.1038/ijo.2012.145 [cited 2019 May 20].

81. Munthali RJ, Kagura J, Lombard Z, Norris SA. Childhood adiposity trajectories are associated with late adolescent blood pressure: birth to twenty cohort. BMC Public Health. 2016;16(1):665. https://doi.org/10.1186/ s12889-016-3337-x [cited 2019 May 19].

82. Salman Z, Kirk GD, Deboer MD. High rate of Obesity-associated hypertension among primary schoolchildren in Sudan. Int J Hypertens. 2011;2011:1-6.

83. Dos Santos FK, Prista A, Gomes TNQF, Santos D, Damasceno A, Madeira A, et al. Body mass index, cardiorespiratory fitness and cardiometabolic risk factors in youth from Portugal and Mozambique. Int J Obes. 2015;39(10): 1467-74 [cited 2019 May 20] Available from: http://www.nature.com/ articles/ijo2015110.

84. Zeelie A, Moss SJ, Kruger HS. The relationship between body composition and selected metabolic syndrome markers in black adolescents in South Africa: The PLAY study. Nutrition. 2010;26(11-12):1059-64 Nov [cited 2019 May 19] Available from: https://inkinghub.elsevier.com/retrieve/pii/ S0899900710000961

85. Nwaiwu O, Ibe BC. Relationship between serum cholesterol and body mass index in Nigeria schoolchildren aged 2-15 years. J Trop Pediatr. 2015;61(2): 126-30. https://doi.org/10.1093/tropej/fmu080 [cited 2019 May 19].

86. Oduwole AA, Ladapo TA, Fajolu IB, Ekure EN, Adeniyi OF. Obesity and elevated blood pressure among adolescents in Lagos, Nigeria: a crosssectional study. BMC Public Health. 2012;12(1):616. https://doi.org/10.1186/ 1471-2458-12-616 [cited 2019 May 19].

87. Omisore B, Omisore AG, Abioye-Kuteyi EA. Gender comparisons of adolescents' anthropometry and blood pressure in Osun State, SouthWestern Nigeria. Int J Adolesc Med Health. 2015;27(3):247-51 [cited 2019 May 20] Available from: https://www.degruyter.com/view/j/ijamh.2015.27. issue-3/ijamh-2014-0018/ijamh-2014-0018.xml.

88. Senbanjo 1O, Oshikoya KA. Obesity and blood pressure levels of adolescents in Abeokuta, Nigeria. Cardiovasc J Afr. 2012;23(5):260-4 [cited 2019 May 20] Available from: http://www.cvja.co.za/onlinejournal/vol23/vol23_issue5/\#/26/.

89. Uwaezuoke SN, Okoli CV, Ubesie AC, Ikefuna AN. Primary hypertension among a population of Nigerian secondary school adolescents: prevalence and correlation with anthropometric indices: a cross-sectional study. Niger J Clin Pract. 2016;19(5):649-54 [cited 2019 May 19] Available from: http:// www.njcponline.com/text.asp?2016/19/5/649/188706.
90. Chedjou-Nono E, Sap S, Choukem S-P, Ngosso Tetanye I, Nebongo D, Koki NO. Cardiometabolic profile of obese children in a sub-Saharan African setting: a cross-sectional study. BMC Pediatr. 2017;17(1):129. https://doi.org/ 10.1186/s12887-017-0880-2 [cited 2019 May 19].

91. Mushengezi B, Chillo P. Association between body fat composition and blood pressure level among secondary school adolescents in Dar es Salaam, Tanzania. Pan Afr Med J. 2014;19 [cited 2019 May 20] Available from: http:// www.panafrican-med-journal.com/content/article/19/327/full/.

92. Kimani-Murage EW, Kahn K, Pettifor JM, Tollman SM, Dunger DB, Gómez-Olivé $X F$, et al. The prevalence of stunting, overweight and obesity, and metabolic disease risk in rural South African children. BMC Public Health. 2010;10(1):158. https://doi.org/10.1186/1471-2458-10-158 [cited 2019 May 19].

93. Negash S, Agyemang C, Matsha TE, Peer N, Erasmus RT, Kengne AP. Differential prevalence and associations of overweight and obesity by gender and population group among school learners in South Africa: a cross-sectional study. BMC Obes. 2017;4(1):29. https://doi.org/10.1186/ s40608-017-0165-1 [cited 2019 May 20].

94. Muhihi AJ, Mpembeni RNM, Njelekela MA, Anaeli A, Chillo O, Kubhoja S, et al. Prevalence and determinants of obesity among primary school children in Dar es Salaam, Tanzania. Arch Public Heal. 2013;71(1):26. https:// doi.org/10.1186/0778-7367-71-26 [cited 2019 May 19].

95. LeBlanc AG, Katzmarzyk PT, Barreira TV, Broyles ST, Chaput JP, Church TS, et al. Correlates of total sedentary time and screen time in 9-11 year-old children around the world: The international study of childhood obesity, lifestyle and the environment. PLoS One. 2015;10(6).

96. Fruhstorfer $\mathrm{BH}$, Mousoulis C, Uthman OA, Robertson W. Socio-economic status and overweight or obesity among school-age children in subSaharan Africa - a systematic review. Clin Obes. 2016;6(1):19-32. https://doi. org/10.1111/cob.12130 [cited 2019 May 19].

97. Frederick CB, Snellman K, Putnam RD. Increasing socioeconomic disparities in adolescent obesity. Proc Natl Acad Sci. 2014;111(4):1338-42.

98. Bloom DE, Cafiero-Fonseca ET, Candeias V, Adashi E, Bloom L, Gurfein L, et al. Economics of non-communicable diseases in India - a report by the World Economic Forum and the Harvard School of Public Health. World Econ Forum Harvard Sch Public Heal [Internet]. 2014; (November). Available from: http://www.sciencedirect.com/science/ article/pii/S0305750X9800059X\%5Cn http://www.jstor.org/stable/44 05541\%5Cn http://documents.worldbank.org/curated/en/2010/10/12932 732/prevention-control-selected-chronic-ncds-sri-lanka-policy-optionsaction\%5Cn http://mail.

99. Muthuri SK, Francis CE, Wachira L-JM, LeBlanc AG, Sampson M, Onywera $V O$, et al. Evidence of an overweight/obesity transition among schoolaged children and youth in Sub-Saharan Africa: a systematic review. PLoS One. 2014;9(3):e92846. https://doi.org/10.1371/journal.pone.0092846 [cited 2019 Mar 18].

100. Malik VS, Willett WC, Hu FB. Global obesity: trends, risk factors and policy implications : article : nature reviews endocrinology. Endocrinology. 2013;9: 13-27 [cited 2019 May 20] Available from: http://www.nature.com/nrendo/ journal/v9/n1/full/nrendo.2012.199.html.

101. Filla Rosaneli C, Auler F, Barreto Manfrinato C, Filla Rosaneli C, Sganzerla C, Gimenes Bonatto $M$, et al. Evaluation of the prevalence and nutritional and social determinants of overweight in a population of schoolchildren: a cross-sectional analysis of 5,037 children. Rev Assoc Méd Br. 2013;58(4):472-6.

102. Mozaffari H, Nabaei B. Obesity and related risk factors. Indian J Pediatr. 2007; 74(3):265-7.

103. Reuter CP, Burgos MS, Bernhard JC, Tornquist D, Klinger El, Borges TS, et al. Association between overweight/obesity in schoolchildren with FTO rs9939609 polymorphism and family history of obesity. J Pediatr. 2016;92(5): 493-8. https://doi.org/10.1016/j.jped.2015.11.005.

104. Daniels SR. The consequences of childhood overweight and obesity. Futur Child. 2006.

105. Kotchen TA. Obesity-related hypertension: epidemiology, pathophysiology, and clinical management. Am J Hypertens. 2010;23(11):1170-8 [cited 2019 May 20] Available from: https://academic.oup.com/ajh/articleabstract/23/11/1170/197863.

106. Dabelea D, reviews CH-N, 2013 undefined. Role of developmental overnutrition in pediatric obesity and type 2 diabetes. academic.oup. com [Internet]. [cited 2019 May 20]; Available from: https://academic. oup.com/nutritionreviews/article-abstract/71/suppl_1/S62/1835250. 
107. El-Karaksy H, Helmy H, Anwar G, El-Hennawy A, El-Koofy N, El-Raziky M, et al. The association of metabolic syndrome, insulin resistance and non-alcoholic fatty liver disease in overweight/obese children. Saudi J Gastroenterol. 2012; 18(1):44 [cited 2019 May 20] Available from: https://www.ncbi.nlm.nih.gov/ pmc/articles/PMC3271694/.

\section{Publisher's Note}

Springer Nature remains neutral with regard to jurisdictional claims in published maps and institutional affiliations.

Ready to submit your research? Choose BMC and benefit from:

- fast, convenient online submission

- thorough peer review by experienced researchers in your field

- rapid publication on acceptance

- support for research data, including large and complex data types

- gold Open Access which fosters wider collaboration and increased citations

- maximum visibility for your research: over $100 \mathrm{M}$ website views per year

At $\mathrm{BMC}$, research is always in progress.

Learn more biomedcentral.com/submissions 